\title{
Acta Orthopaedica Scandinavica
}

\section{Impacted morsellized bone grafting and cemented primary total hip arthroplasty for acetabular protrusion in patients with rheumatoid arthritis: An 8- to 18-year follow-up study of 36 hips}

\author{
Wout W J Rosenberg, B Willem Schreurs, Maarten C De Waal Malefijt, René P \\ $\mathrm{H}$ Veth \& Tom J J H Slooff
}

To cite this article: Wout W J Rosenberg, B Willem Schreurs, Maarten C De Waal Malefijt, René P H Veth \& Tom J J H Slooff (2000) Impacted morsellized bone grafting and cemented primary total hip arthroplasty for acetabular protrusion in patients with rheumatoid arthritis: An 8- to 18-year follow-up study of 36 hips, Acta Orthopaedica Scandinavica, 71:2, 143-146, DOI: 10.1080/000164700317413102

To link to this article: http://dx.doi.org/10.1080/000164700317413102

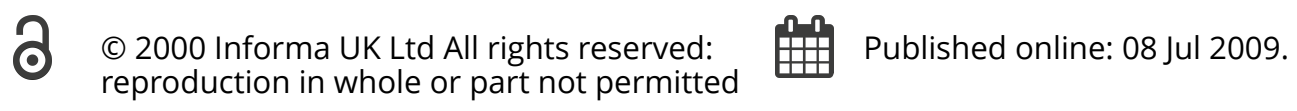

Submit your article to this journal ๔ 


\title{
Impacted morsellized bone grafting and cemented primary total hip arthroplasty for acetabular protrusion in patients with rheumatoid arthritis
}

\author{
An 8- to 18-year follow-up study of 36 hips
}

\author{
Wout W J Rosenberg, B Willem Schreurs, Maarten C de Waal Malefijt, René P H Veth \\ and Tom J J H Slooff
}

Department of Orthopaedics, University Hospital Nijmegen, P.O. Box 9101, NL-6500 HB Nijmegen, The Netherlands. Tel +31-243-613974. Fax -540230. Correspondence: Dr. B W Schreuers

Submitted 99-03-02. Accepted 99-11-30

\begin{abstract}
Between 1979 and 1989, we performed 36 primary total hip replacements in 31 rheumatoid arthritis patients with protrusio acetabuli. The deficient acetabulum was reconstructed with autologous morsellized bone grafts from the femoral head. 3 patients were lost to follow-up.

12 patients (13 hips) died within 8 years postoperatively, none had a revision. 16 patients (20 hips) were reviewed at an average follow-up of 12 (8-18) years.

In 2 hips, a revision was performed for aseptic loosening of the acetabular component, 6.5 and 8 years after primary surgery, which means a $90 \%(95 \%$ CI: $77 \%-$ $100 \%$ ) survival rate at 12 years (Kaplan Meier analysis). This technique is a good option in cases with protrusio acetabuli due to rheumatoid arthritis.
\end{abstract}

In many patients with advanced rheumatoid arthritis the acetabular bone stock loss results in protrusio. Impacted morsellized bone grafting in these patients proved to be a successful procedure to arrest protrusio in short-term follow-up studies (Hastings and Parker 1975, McCollum et al. 1980, Johnsson et al. 1984). We have previously presented our short-term results in 23 patients with 27 acetabular reconstructions and a cemented total hip arthroplasty (Kinzinger et al. 1991). We have now analyzed the outcome in all our patients with a follow-up of 8 years or more.

\section{Patients and methods}

From 1979 to 1989 , we performed 36 primary total hip arthroplasties with an acetabular reconstruction in 31 rheumatoid patients with acetabular bone defects. At the time of review (December 1997), 3 patients ( 3 hips) had been lost to followup, leaving 33 hips in 28 patients ( 21 women, 7 men).

To classify the acetabular defects, we used the classification system of the American Academy of Orthopaedic Surgeons (AAOS) Committee on the Hip (D’Antonio et al. 1989). Defects were estimated, using the pre- and postoperative radiographs and the surgical notes.

An acetabular cavitary defect was seen in 23 hips, and a combined segmental-cavitary defect in 10 hips (9 segmental medial, 1 peripheral defect).

The incorporation of the graft was determined on standard radiographs, according to the criteria of Conn et al. (1985). Demarcation at the interface was classified according to DeLee and Charnley (1976), with a radiolucent line of at least $2 \mathrm{~mm}$. Migration of the acetabular component in the vertical direction was measured between the center of the cup and the line connecting the two teardrops. Horizontal migration was measured between the vertical line through the teardrop and the center of the cup. The definition of radiographic failure was progressive radiolucency in 3 zones or migration more than $5 \mathrm{~mm}$ in any direction on conventional AP radiographs. 


\section{Patient details}

\begin{tabular}{|c|c|c|c|c|c|c|c|c|}
\hline Case & $A$ & B & C & $\mathrm{D}$ & $E$ & $F$ & $\mathrm{G}$ & $\mathrm{H}$ \\
\hline 1 & 57 & $\mathrm{~F}$ & $\mathrm{R}$ & 111 & 1 & + & - & - \\
\hline 2 & 37 & $M$ & $L$ & 129 & 1 & + & - & - \\
\hline 3 & 37 & $M$ & $\mathrm{R}$ & 129 & 1 & + & - & - \\
\hline 4 & 79 & $\mathrm{~F}$ & $\mathrm{~L}$ & 99 & 1 & + & - & - \\
\hline 5 & 62 & $\mathrm{~F}$ & $\mathrm{~L}$ & 131 & 1 & + & - & - \\
\hline 6 & 70 & $M$ & $\mathrm{R}$ & 120 & 1 & + & - & I \\
\hline 7 & 70 & $M$ & $L$ & 120 & 1 & + & - & - \\
\hline 8 & 62 & $\mathrm{~F}$ & $\mathrm{~L}$ & 96 & 1 & + & + & |-II-III \\
\hline 9 & 55 & $\mathrm{~F}$ & $\mathrm{R}$ & 210 & 1 & - & - & 1 \\
\hline 10 & 53 & $F$ & $L$ & 194 & 1 & - & - & I \\
\hline 11 & 53 & $\mathrm{~F}$ & $\mathrm{~L}$ & 188 & 1 & + & - & - \\
\hline 12 & 23 & $\mathrm{~F}$ & $\mathrm{~L}$ & 158 & 3 & + & - & I \\
\hline 13 & 20 & $M$ & $\mathrm{~L}$ & 164 & 3 & - & - & III \\
\hline 14 & 23 & $\mathrm{~F}$ & $\mathrm{R}$ & 77 & 3 & + & + & |-II-III \\
\hline 15 & 71 & $F$ & $\mathrm{R}$ & 155 & 2 & + & - & - \\
\hline 16 & 34 & F & $\mathrm{R}$ & 151 & 2 & + & - & - \\
\hline 17 & 40 & $\mathrm{~F}$ & $\mathrm{~L}$ & 149 & 1 & + & - & - \\
\hline 18 & 58 & $\mathrm{~F}$ & $L$ & 147 & 2 & + & - & - \\
\hline 19 & 77 & $\mathrm{~F}$ & $\mathrm{R}$ & 120 & 1 & - & - & - \\
\hline 20 & 62 & $\mathrm{~F}$ & $\mathrm{~L}$ & 123 & 1 & + & - & - \\
\hline 21 & 58 & $\mathrm{~F}$ & $\mathrm{R}$ & 42 & 1 & + & - & - \\
\hline 22 & 77 & $\mathrm{~F}$ & $\mathrm{~L}$ & 38 & 1 & + & - & - \\
\hline 23 & 77 & $M$ & $\mathrm{~L}$ & 39 & 1 & + & - & - \\
\hline 24 & 78 & V & $\mathrm{R}$ & 35 & 1 & + & - & - \\
\hline 25 & 72 & $\mathrm{~F}$ & $\mathrm{R}$ & 59 & 1 & + & - & - \\
\hline 26 & 70 & $\mathrm{M}$ & $L$ & 52 & 1 & + & - & I \\
\hline 27 & 69 & $\mathrm{~F}$ & $\mathrm{~L}$ & 44 & 1 & + & - & - \\
\hline 28 & 45 & $\mathrm{M}$ & $\mathrm{R}$ & 52 & 1 & + & - & - \\
\hline 29 & 45 & $\mathrm{M}$ & $\mathrm{L}$ & 51 & 1 & - & - & - \\
\hline 30 & 49 & $\mathrm{~F}$ & $\mathrm{R}$ & 65 & 1 & - & - & - \\
\hline 31 & 56 & $M$ & $\mathrm{R}$ & 48 & 1 & + & - & - \\
\hline 32 & 64 & $\mathrm{~F}$ & $\mathrm{~L}$ & 82 & 1 & + & - & - \\
\hline 33 & 69 & $\mathrm{~F}$ & $\mathrm{R}$ & 29 & 1 & + & - & - \\
\hline
\end{tabular}

\author{
A Age at time of operation \\ B Gender \\ C Side \\ D Follow-up in months \\ E Rh serology \\ 1 positive \\ 2 negative \\ 3 juvenile RA \\ F Vitallium metal wire mesh \\ G Revision \\ $\mathrm{H}$ Radiolucent zone around cup at follow-up, according \\ to DeLee and Charnley (1976)
}

The posterolateral approach was used in all cases. In all reconstructions, we used the patient's own femoral head which was morsellized with a rongeur, creating grafts measuring $0.5-1 \mathrm{~cm}$ (Slooff et al. 1984). In segmental defects in the medial wall, a cortico-cancellous graft was used to close the gap. The morsellized grafts were impacted into the acetabular defect, with the socket trial prosthesis as impactor and mould. In 27 cas- es, a vitallium metal wire mesh was placed on top of the bone graft. The center of rotation was always restored to normal. The $32 \mathrm{~mm}$ polyethylene Mueller or Allopro cup was cemented (Palacos R bone cement). Postoperative treatment included systemic antibiotics for 5 days. All patients had a 6 -week period of bed rest and partial weight-bearing up to 3 months.

\section{Results}

12 patients had died less than 8 years after the total hip replacement. None of them had had a revision of the hip and all died of causes not related to the operation. In all, 16 patients (20 hips) were available for follow-up more than 8 years after acetabular reconstruction. There were 13 women and 3 men; 4 patients had had bilateral operations. The average age at operation was $53(20-79)$ years. The mean observation time was 11.7 (8-18) years.

There were no revisions due to infection. However, 2 acetabular components had been revised for aseptic loosening. These revisions were performed 6.5 and 8 years after surgery, respectively. 1 case involved a 23-year-old girl (case 14) who showed progressive radiographic failure within 3 years. The other case (case 8) was a 62-year-old woman who functioned well for 7 years. However, the cup became loose at the cup-bone graft interface, with minimal signs of radiographic failure. At revision, the bone quality of the grafted area was good.

Apart from the 2 revised cases, no radiograph of the original 33 hips showed a failure. Within 3 months after surgery, 6 hips had an interface demarcation of $2 \mathrm{~mm}$. These radiolucent lines were all located in one zone and no progression occurred during radiographic follow-up (Table). In all cases, radiographs showed that the impacted morsellized bone grafts had become incorporated with the surrounding bone.

Kaplan Meier analysis indicated that the longterm survival rate for primary hip arthroplasty, in rheumatoid arthritis patients having a protrusio acetabuli and an acetabular reconstruction with impacted morsellized bone grafts, is $90 \%$ (95\% confidence interval $77 \%-100 \%$ ) at average 12 

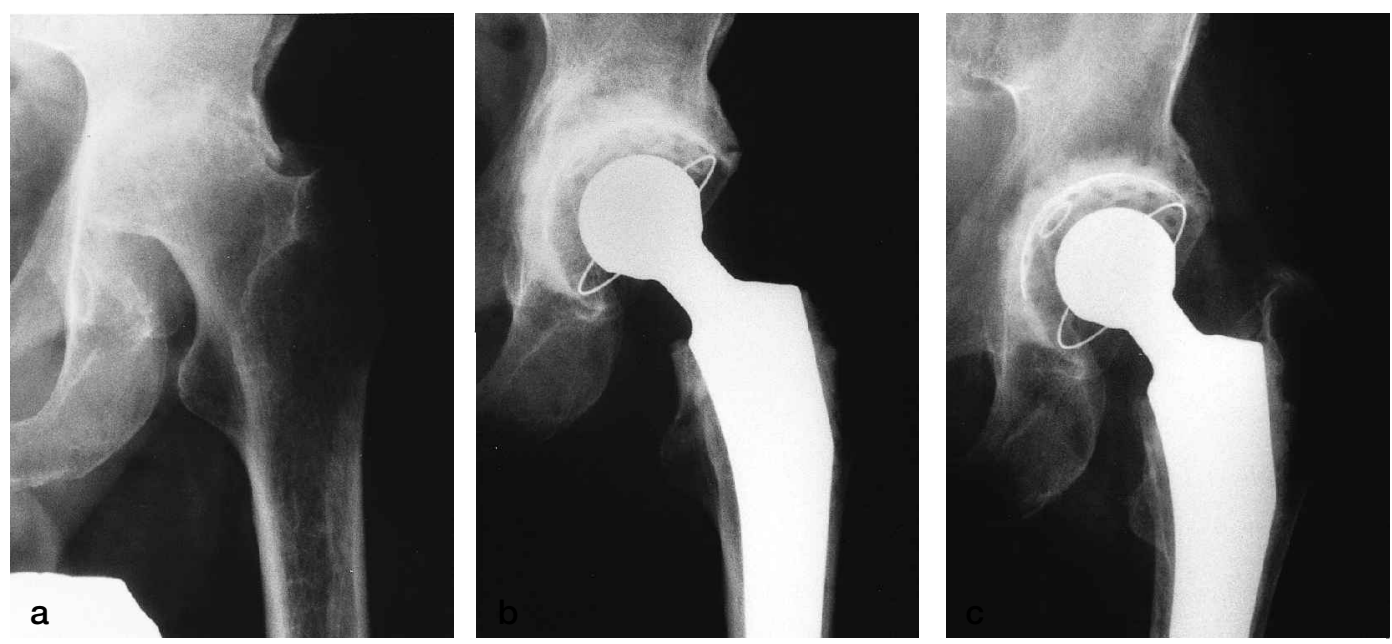

Case 5. A 62-year-old woman with protrusion, preoperatively (a), 2 months postoperatively (b) and 10 years after operation (c). Incorporation of the graft and no signs of radiolucency.

years follow-up using revision as end-point. With a revision or radiographic failure as end-point, this percentage remains $90 \%$. In a worst-case scenario, considering also loss to follow-up as failure, the overall survival rate is $86 \%$.

\section{Discussion}

A lower hip arthroplasty survival rate can be expected in rheumatoid patients (Malchau and Herberts 1998). The outcome in young women with rheumatoid arthritis is especially unfavorable.

Impacted morsellized bone grafting in these patients has proved to be a successful procedure to arrest protrusio in short and medium-term followup studies (Hastings and Parker 1975, Ranawat et al. 1980, Johnsson et al. 1984, Gates et al. 1990, Kinzinger et al. 1991). We have used this technique of bone impaction grafting since 1979 for primary and revision THA.

The survival rate in this group of rheumatoid patients of relatively young age was $90 \%$ with an average follow-up of 12 years. Recently, we have presented our results with this technique in primary and revision total hip arthroplasty for arthrosis mainly. In primary THA, the survival rate for aseptic loosening using an autograft was $94 \%$ at an average follow-up of 13 years (Welten et al., in press). From experimental data, we expected that the outcome of these reconstructions with au- tografts would be better than with allografts. However in revision THA using femoral head allografts, the results are comparable to primary THA, with a survival rate of $94 \%$ for aseptic loosening at 12 years (Schreurs et al. 1998).

In all cases, incorporation of the bone graft occurred during radiographic follow-up, according to the criteria of Conn (1985), but we admit that these criteria are difficult to interpret (Heekin et al. 1995, Schimmel et al. 1998). It is questionable whether one can assess bone incorporation from plain radiographs. However, histological analysis in humans and animals with impacted bone-grafting showed a progressive vascular ingrowth in the graft, a new trabecular structure followed by normal trabecular bone and finally complete incorporation of the graft (Schreurs et al. 1994, 1996, Heekin et al. 1995, Buma et al. 1996, Schimmel et al. 1998).

We conclude that acetabular reconstruction with impacted morsellized autologous bone is effective in rheumatoid patients with protrusio acetabuli. However, when using this technique on the acetabular side, the chip size should be $6-10 \mathrm{~mm}$, smaller chips tend to cause more acetabular migration (Verdonschot et al. 1999).

Buma P, Lamerigts N, Schreurs B W, Gardeniers J, Versleyen D, Slooff T J J H. Impacted graft incorporation after cemented acetabular revision. Acta Orthop Scand 1996; 67: 536-40. 
Conn R A, Peterson L F A, Stauffer R N, Ilstrup D. Management of acetabular deficiency; long-term results of bone grafting the acetabulum in total hip arthroplasty. Orthop Trans 1985; 9: 451-2.

D'Antonio J A, Capello W N, Borden L S, Bargar W L, Bierbaum B F, Boettcher W G, Steinberg M E, Stulberg $\mathrm{S} \mathrm{D}$, Wedge J H. Classification and management of acetabular abnormalities in total hip arthroplasty. Clin Orthop 1989; 243: 126-37.

DeLee J G, Charnley J. Radiological demarcation of cemented sockets in total hip replacement. Clin Orthop 1976; 121: 20-32.

Gates H S, McCollum D E, Nunley J A. Bone grafting in total hip arthroplasty for protrusio acetabuli. J Bone Joint Surg (Am) 1990; 72: 248-52.

Hastings D E, Parker S M. Protrusio acetabuli in rheumatoid arthritis. Clin Orthop 1975; 108: 76-84.

Heekin R D, Engh C A, Vinh T. Morsellized allograft in acetabular reconstruction. A postmortem retrieval analysis. Clin Orthop 1995; 319: 184-90.

Johnsson R, Ekelund L, Zygmunt S, Lidgren L. Total hip replacement with spongious bone graft for acetabular protrusion in patients with rheumatoid arthritis. Acta Orthop Scand 1984; 55: 510-3.

Kinzinger P J M, Karthaus R P, Slooff T J J H. Bone grafting for acetabular protrusion in hip arthroplasty. Acta Orthop Scand 1991; 62 (2): 110-2.

Malchau H, Herberts P. Prognosis of total hip replacement. Presented at the AAOS meeting February 1998, New Orleans, USA.

McCollum D E, Nunley J A, Harrelson J M. Bone-grafting in total hip replacement for acetabular protrusion. J Bone Joint Surg (Am) 1980; 62: 1065-72.
Ranawat C S, Dorr L D, Inglis A E. Total hip arthroplasty in protrusio acetabuli of rheumatoid arthritis. J Bone Joint Surg (Am) 1980; 62: 1059-64.

Schimmel J W, Buma P, Versleyen D, Huiskes R, Slooff T J J H. Acetabular reconstruction with impacted morsellized cancellous bone grafts in cemented revision hip arthroplasty: a histological and biomechanical study on the goat. J Arthroplasty 1998; 13: 438-48.

Schreurs B W, Buma P, Huiskes R, Slagter I L M, Slooff T J J H. Morsellized allografts for fixation of the hip femoral component. Acta Orthop. Scand. 1994; 65: 26775.

Schreurs B W, Huiskes R, Buma P, Slooff T J J H. Biomechanical and histological evaluation of a hydroxyapatite-coated femoral stem fixed with a morsellized bone grafting technique. Biomaterials 1996; 17: 1177-86.

Schreurs B W, Slooff T J J H, Buma P, Gardeniers J W M, Huiskes R. Acetabular reconstruction with impacted morsellised cancellous bone graft and cement. A 10- to 15-year follow-up of 60 revision arthroplasties. J Bone Joint Surg (Br) 1998 ;80: 391-5.

Slooff T J J H, Huiskens R, Horn van J, Lemmens A J. Bone grafting in total hip replacement for acetabular protrusion. Acta Orthop Scand 1984; 55: 593-6.

Verdonschot N, Schreurs B W, Van Unen J M J, Slooff T J J H, Huiskes R. Cup stability after acetabulum reconstruction with morsellized grafts is less surgically dependent when larger grafts are used. Trans. ORS 1999; 24: 867.

Welten M L M, Schreurs B W, Buma P, Verdonschot N, Slooff T J J H. Long-term results of acetabular reconstruction with impacted morsellised bone grafts and primary total hip arthroplasty. Accepted J. Arthroplasty. 